- LA-UR- $95-259 \overline{9}$

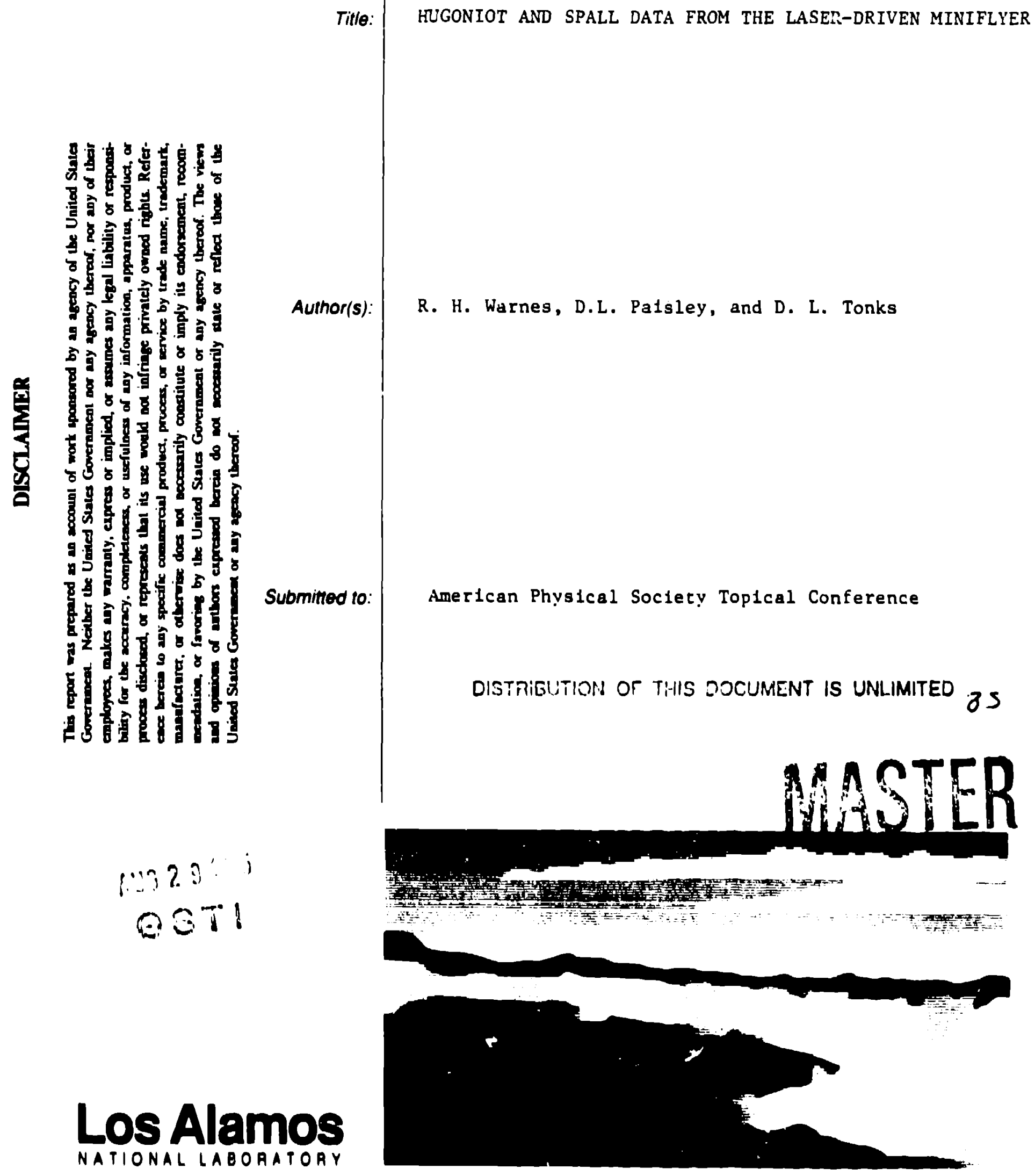

NATIONAL LAOORATORY

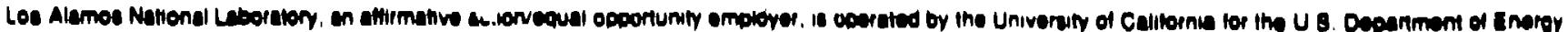

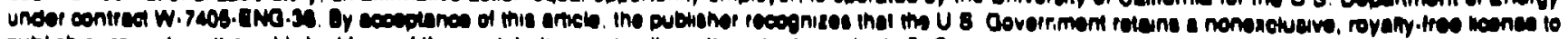

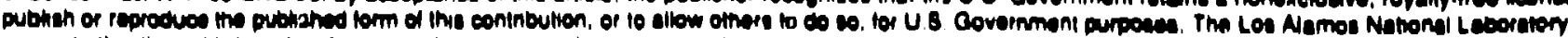

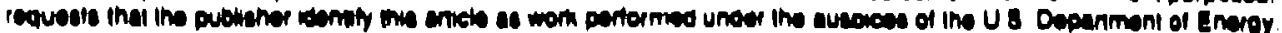




\title{
HUGONIOT AND SPALL DATA FROM THE LASER-DRIVIN MINIFLYER
}

\author{
R. H. Warnes, D. L. Paisley, and D. L. Tonks \\ Los Alamos Natlonal Laboratery, Los Alamos, NM 87545
}

\begin{abstract}
The laser-driven miniflyer has been developed as a small-sized complement to the propellant- or gasdriven gun with which to make material property measurements. Flyer velocities typically range from 0.5 to $1.5 \mathrm{~km} / \mathrm{s}$, depending on the energy of the launching laser and the flyer dimensions. The 10-50 $\mu \mathrm{m}$-thick flyers, $1-3 \mathrm{~mm}$ in diameter, and comparably small targets require very little material and are easy to recover for post-experiment analysis. To measure and irrprove the precision of our measurements, we are conducting an extensive series of experiments impacting well-characterized $\mathrm{Cu}$, $\mathrm{Al}$, and Au on several transparent, calibrated, windows (PMMA, LiF, and sapphire). Measurement of the impact and interface velocities with a high-time-resolution velocity interferometer (VISAR) gives us a point on the Hugoniot of the flyer material. These are then compared to published Hugoniot data taken with conventional techniques. In the spall experiments, a flyer strikes a somewhat thicker target of the same material and creates a spall in the target. Measuring the free-surfac: velocity of the target gives information on the compressive elastic-plastic response of the target to the impact, the tensile spall strength, and the stroin rate at which the spall occurred. Volumetric strain rates at spall in these experiments are frequently in the $10^{6}-10^{8} \mathrm{~s}^{-1}$ range, considerably higher than the $10^{3}-10^{4} \mathrm{~s}^{-1}$ range obtainablc from gas gun experiments.
\end{abstract}

\section{INTRODUCTION}

The Laser-driven Miniflycr has been developed over the last several years to measure the dynamic properties of materials under shock-wave conditions. A pulsed Nd:YAG laser is focused through a transparent substrate onto a thin multilayer that has been deposited on the substrate, Fig. 1. A thin foil (the flyer) is placed on the multilayer. The laser pulse is absorbed in the multilayer and creales a plasma. which in lurn accelerates the flyer to its terminal velocity within three or four pulse widths of the laser. The nearly perfectly flat flyer then impacts a target and the response of the flyer and target after the impact are measured with a high-time-resolution laser velocity interferometer (VISAR) (1-2). Many of the material properties that are routinely determined with propellant- or gas-driven guns or explosives can be obtained with the Miniflyer.

Because the flyers and largets are very simall (10$50 \mu \mathrm{m}$ thick and 1 to $3 \mathrm{~mm}$ in diameler), recovery of the samples for post-shot analysis is straightforward. The amount of material needed for an experiment is also quite small-a definite advantage if the material being studied is toxic and/or expensive.

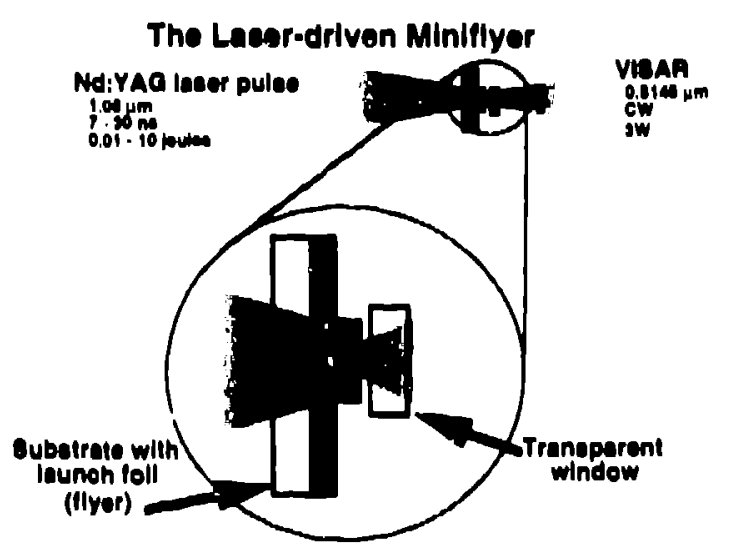

FICi RE: I. A schematic of the l.aver-driven Minillyer. 'I'he launching laser enters from the letl, and ine diagnosiclic laser cnters liom the right 
Some details of the Miniflyer launch and the direct optical recording of the VISAR data have been presented previously (3-4). The purpose of this paper is to describe the data analysis and to compare the results with. data obtained by conventional techniques. The experiments discussed here are just the first few of many scheduled to determine if the assembly and alignment procedures and the precision of the measurements are adequate to determine accurate Hugoniots and spall-related properties. In addition we hope to determine the effect of scaling, if any, on the properties being measured.

\section{HUGONIOT EXPERIMENTS}

In these experiments the material to be studied, the "unknown". is the flyer-a 25- $\mu \mathrm{m}$-thick foil of OFHC Cu in the as-received state of hardness. The target is one of several transparent window materials of known Hugoniot and calibrated for use with the VISAR in shock-wave experiments (5-6). PMMA, Lif, and sapphire are used. The VISAR is focused through the window and onto the flyer, Fig. I. Before impact the velocily history of the flyer is recorded, after impact the flyer/target interface velocity is recorded, Fig. 2. From these two measure. ments, a point on the Hugoniot of the "unknown" nyer can be calculated.

Figure 3 shows graphically how a point on the flyer Hugoniot is determined from the impact and interface velocities. The measured impact velocity

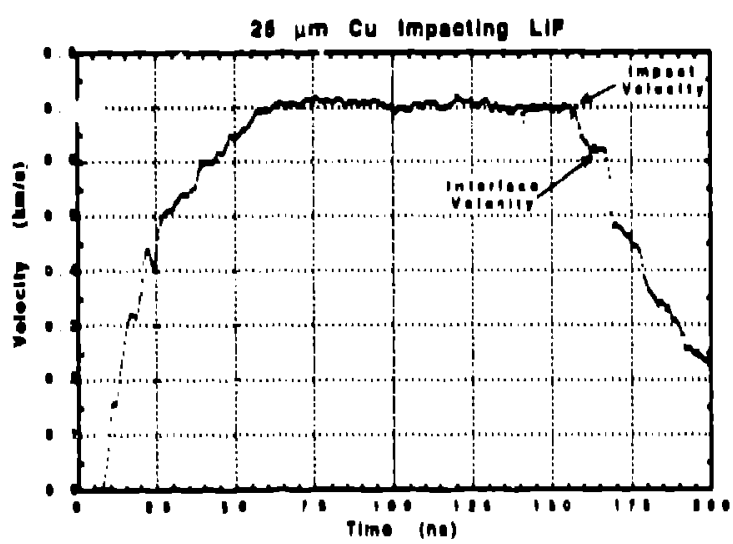

HICI'RE: 2. Velocils dali from the VISAR The datn required

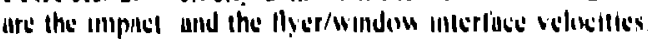

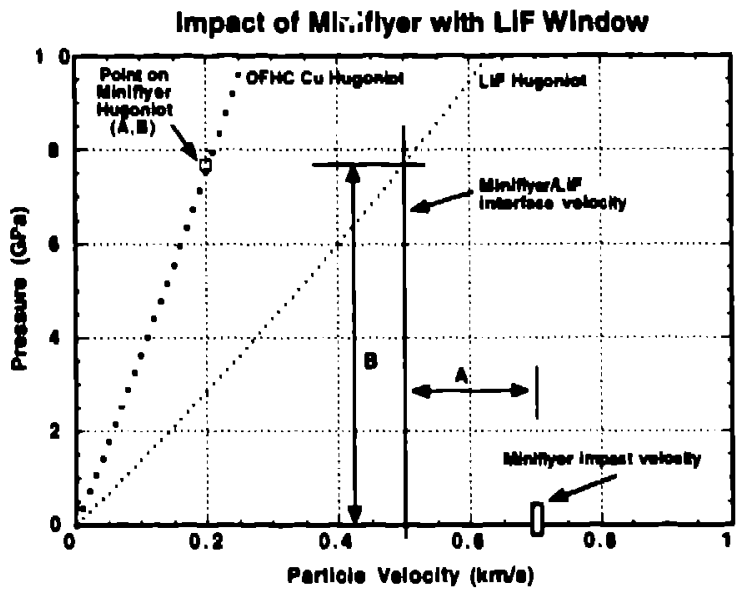

FIGIRE 3. Graphicul representation of the data analysis From the nyer and intertace velocities, a point on the nyer Hugoniot may be determined.

is shown as a rectangle on the particle velocity axis at $0.7 \mathrm{~km} / \mathrm{s}$. The measured interface velocity is corrected for the window effecis (5-6) and then shown in Fig. 3 as the vertical line at a particle velocity of $0.5 \mathrm{~km} / \mathrm{s}$. The pressure at the flyer/target interface, $B$, is determined by the intersection of this vertical line and the window (in this case, LiF) Hugoniot. If the impact velocity minus the actual interface velocity is $A$, the coordinates of a point on the flyer Hugoniot are $(A, B)$

The measured Hugoniot of the flyer Inaterial is

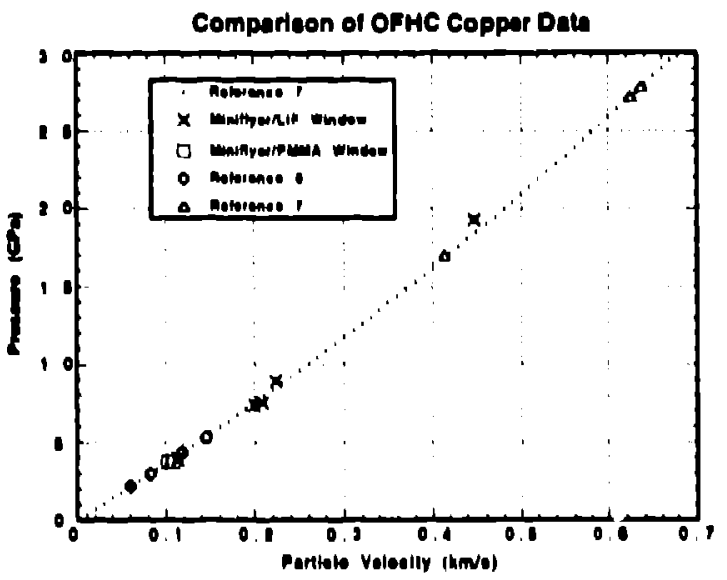

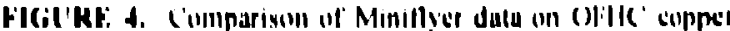
with published Jata. lill and leMMiA wimdins Hele used in thesc experiments 
TABLE 1. MIninyer Experiments, Calculations, and Comparisons

\begin{tabular}{|c|c|c|c|c|c|c|c|}
\hline $\begin{array}{c}\text { Experiment } \\
\text { No. }\end{array}$ & $\begin{array}{l}\text { Window } \\
\text { Material }\end{array}$ & $\begin{array}{c}\text { Impact } \\
\text { Velocity } \\
(\mathrm{km} / \mathrm{s})\end{array}$ & $\begin{array}{c}\text { Interface } \\
\text { Velocily } \\
(\mathrm{km} / \mathrm{s})\end{array}$ & $\begin{array}{c}\text { CTH } \\
\text { Interface } \\
\text { Velocity } \\
(\mathrm{km} / \mathrm{s})\end{array}$ & $\begin{array}{c}\text { Measured } \\
\text { Hugoniot } \\
{ }_{\text {up. } P} \\
(\mathrm{~km} / \mathrm{s}, \mathrm{GPa})\end{array}$ & $\begin{array}{c}\text { OFHC Cu } \\
\text { Hugoniot } \\
\text { Up. P } \\
(\mathrm{km} / \mathrm{s} . \mathrm{GPa})\end{array}$ & $\begin{array}{c}\text { Difference } \\
\text { in } \\
\text { Pressure } \\
\%\end{array}$ \\
\hline I & LiF & 0.679 & 0.480 & 0.483 & $0.200,7.341$ & $0.200,7.556$ & 2.9 \\
\hline$?$ & LiF & 0.793 & 0.570 & 0.563 & $0.223,8.907$ & $0.223,8.507$ & 4.5 \\
\hline 3 & LiF & 0.382 & 0.269 & 0.273 & 0.113 .3 .918 & $0.113,4.146$ & 5.8 \\
\hline 4 & LiF & 0.697 & 0.490 & 0.496 & $0.208,7.511$ & $0.208,7.894$ & 5.1 \\
\hline 5 & LiF & 1.547 & 1.099 & 1.087 & $0.448,19.25$ & $0.448, \quad 18.431$ & 4.3 \\
\hline 6 & PMMA & 0.930 & 0.821 & 0.827 & 0.109 .3 .735 & $0.109,3.993$ & 6.9 \\
\hline 7 & PMMA & 0.921 & 0.819 & 0.818 & $0.102,3.724$ & $0.102,3.735$ & 0.3 \\
\hline
\end{tabular}

compared to published OFHC Hugoniot data in Fig. $4(7-8)$. The parameters that can be varied to get a range of pressures and particle velocities on the Hugoniot of the flyer material are the impact velocity of the flyer (adjusted by changing the flyer thickness and the energy in the Nd:YAG laser pulse) and the impedance of the window used for the target.

The CTH code (9) has been used 10 model the fyer'target interaction. Table I. gives some details of the small but representative set of experiments plotted in Fig. 4 and shows the agreement between the measured and calculated interface velocities.

\section{SPALL ANALYSIS}

The miniflyer wave profile data can be analyzer! by wave code computer simulation. Information aboul the plasticity in the shock rise and release, as well as spall strength, can be extracted. To demonstrate this process, we present a simulation result of an early miniflyer experiment on aluminum.

Figure 5 shows the paricle velocity data taken by a VISAR on the free surface of a sample foil of Reynolds aluminum nominally $50 \mu \mathrm{m}$ thick. The flyer plate was launched from a substrate coated with a layer of vapor-deposited Al nominally $25 \mu \mathrm{m}$ thick. The metallurgical properties of both ficils are not well known.

ligure 5 also shows the result of a simulation using the characteristics wave code CHARADE: (10). The materials modeling included the Johnson-Barker model for the plastic strain rate in the plasile rise (II). a backstress model for the reverse plastic llow in the release (12), and a pressure threshold spall model. The K:OS used was a Mle-cirueneisen type with a pressure dependent bulk modulus und con-

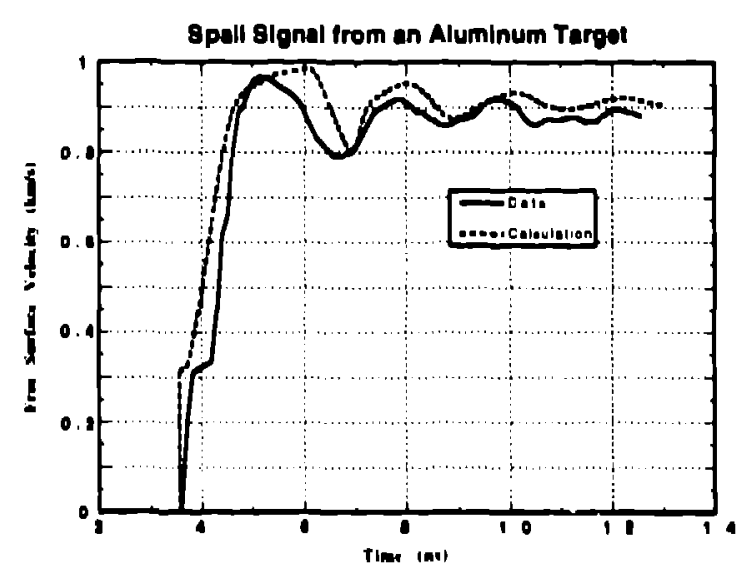

Figure 5. Comparison of frec surface velocity data from a spalled aluminum target with a ('HARADL: wave code simula. lion.

stant Poisson's ratio (13). The equation of state material parameters used were roughly appropriate for $606 \mathrm{l}-\mathrm{T} 6 \mathrm{Al}$. Using parameters for $2024 \mathrm{Al}$ and 1100 Al produced little change in the calculated free surtace velocity profilic.

The volumetric tensile spall strength was found to be $1.8 \mathrm{GPa}$. This value, because it was obtained from a full hydro calculation in CHARADE. takes into account the wave evolution between the spall plane and the free surface. A calculated value of 2.8 (jPa was found for a gas gun experiment on 6061. T'GAl (13)

In the calculation. the llyer plate impact velocity was taken to be the observed free surlace peak particle velocity, since the Impact valocity was not measured independently. This velocity produced a filirly good overall :omparison with the liree surface velocity duta, as seen in Fig. S.. The fit of calcuintion to Jata was done only on a qualitative 
basis since the cxperiment is not well characterized. The various materials models were adjusted to demonstrate that the general features in the data are reproducible with CHARADE, as seen in the figure.

It is of interest to compare the materials parameters arrived at in the fitting with their counterparts from a simulation of gas gun data on $6061 \mathrm{~T} 6 \mathrm{Al}$ at a shock strength of aboul $4.3 \mathrm{GPa}$ and involving much larger plate dimensions (13). In the miniflyer fit, the plastic strain rate multiplier had to be increased ten fold and the dislocation multiplication right after the precursor had to be decreased by about 7 fold from the gas gun fits. In the backstress model, the miniflyer fit required about a seven fold smaller dislocation viscosity and a twenty fold increase in pinned dislocation density. The miniflyer fitting seems consistent with the sample foil being in a strongly work hardened state from its rolling preparation, and, therefore, having a large initial dislocation density.

The calculated volumetric strain rate for the miniflyer spall was about $7.6 \times 10^{7} \mathrm{~s}^{-1}$, many orders of magnitude above that of gas gun experiments. The high spallation strain rate obtainable in the miniflyer experiment is another example of the advantages this technique has to offer.

\section{ACKNOWI.EDGMENTS}

We wish to thank Stephen Sheffield for constructive suggestions in the design of the experiments and David Stahl for his help in conducting them. This work is supported by the United States Department of Energy unjer Contract W-7405-ENG. 36.

\section{REFERENCES}

I. Barker. L. M. anci Hollenbach, R. E, J. Appl. Phys. 43, 4669-4675, (1972)

2. Hemsing. W, F., Rev. Sci, Insirum. SO(1), 73-78, (1979)

3. Paisley, D. L. Warnes, R. H.. and Kopp. R. A.. "Laserdriven flat plate impacts to $100 \mathrm{GPa}$ with sub-nanosecond pulse duration and resolution for material property studies." Shack Compression of Condensed Maller-1991." 825-828. Williamsburg. VA

4. Paisley. D. L.. Warnes, R. H., and Stahl, D. B., SPIE 2273. 167-172, (1994).

5. Barker, L. M. and Hollenbach, R. E., J. Appl. Phys. 41 . 4208-4226, (1970).

6. Wise. J. L. and Chhabildas, L. C. "Laser interferometer measurements of refractive index in shock-compressed materials," Shack Waves in Condensed Maller, 441-454, Spokane, WA, (1985).

7. McQueen, R. G., Marsh, S, P., Taylor, J. W., Fritz, J. N., and Carter, W. J., Migh-l'elocity Impuct Phenomena, New York. Academic Press, 1970, ch. 7.

8. Munson, D. E. and Barker. L. M. J. Appl. Phys. 37, 16521660. (1966)

9. CTH is a code system under evelopment at Sandia National l.aboralory to model multi-dimensional, multimaterial, large deformation, strong shock physics. Funther information can be ubtained fron ("rli Development Project. Department 1431. Sendia National l.aboratorics. Albuquerqus, New Mexico, 87/85.0819.

10. Johnson, J. N. and l'onks, D I... "CllaradF: A Characteristic Code for Calculating Rate-Dependent Shock-Wave Response." I.os Alamos Report L.A.11993. MS. 1991

11. Johnsun, J N., and Harker. I. M., J. Appl. Phys. 40. 432 I4334 (1969).

12. Johnson, J. N., Ilixson, K. S. Tonks, D. L... and Gray. (i. T. III. "Shock Cumpression and Quasielastic Release in Tantalum." High-Pressure Siclence and Technolog! 1993. pp. 109.5-1098. Colorado Springs. (c)

13. Johnson, J. N. Ilixson. K S.. and (iray, (i. TI, III, J. Appl Iths. 76. $5706-5718(1949)$ 